\title{
Practical Considerations Regarding Power Factor for Nonlinear Loads
}

\author{
Mohamed Mamdouh Abdel Aziz, Member, IEEE, Essam El-Din Abou El-Zahab, Ahmed Mohamed Ibrahim, and \\ Ahmed Faheem Zobaa, Member, IEEE
}

\begin{abstract}
The choice of $L C$ compensator may be constrained by the availability of manufactures units. To account for this, the capacitor values are chosen from among standard values and for each value the transmission losses is minimized, or power factor is maximized, or transmission efficiency is maximized. The global minimum or maximum is obtained by scanning all local minims or maxims. The performance of the obtained compensator is discussed by means of numerical examples.
\end{abstract}

Index Terms-Harmonics, power factor, reactive power.

\section{NOMENCLATURE}

$\mathrm{R}_{\mathrm{LK}}, \mathrm{X}_{\mathrm{LK}} \quad$ Load resistance and reactance at harmonic number K (in ohms).

$\mathrm{G}_{\mathrm{LK}}, \mathrm{B}_{\mathrm{LK}} \quad$ Load conductance and susceptance at harmonic number $\mathrm{K}$ (in ohms).

$\mathrm{R}_{\mathrm{TK}}, \mathrm{X}_{\mathrm{TK}} \quad$ Transmission system resistance and reactance at harmonic number $\mathrm{K}$ (in ohms).

$\mathrm{X}_{\mathrm{L}}, \mathrm{X}_{\mathrm{C}}$

$\mathrm{R}$ Fundamental inductive and capacitive reactance of the compensator (in ohms).

$\mathrm{I}_{\mathrm{SK}}$

$\mathrm{I}_{\mathrm{S}}$

$\mathrm{I}_{1 \mathrm{~K}}$

$\mathrm{I}_{\mathrm{LK}}$

$\mathrm{I}_{\mathrm{CK}}$

$\mathrm{P}_{\mathrm{L}}$

$\mathrm{P}_{\mathrm{S}}$

$\mathrm{V}_{\mathrm{LK}}$

$\mathrm{V}_{\mathrm{SK}}$

$\mathrm{V}_{\mathrm{L}}$

$\mathrm{f}_{\mathrm{O}}$

Resistance of the compensator reactor (in ohms).

Supply current at harmonic number K (in amps).

RMS value of supply current (in amps).

Load current at harmonic number K (in amps). Load harmonic current (in amps).

Capacitor current at harmonic number K (in amps).

Load power (in watts).

Supply power (in watts).

Load voltage at harmonic number $\mathrm{K}$ (in volts).

Supply voltage at harmonic number K (in volts).

RMS value of load voltage (in volts).

Frequency (in Hertz).

$\mathrm{rad} / \mathrm{s}$.

\section{INTRODUCTION}

$\mathbf{S}$ EVERAL methods have been proposed for optimal power factor correction at nonlinear loads [1]-[11]. The procedures used by these references accounted for harmonics

Manuscript received September 30, 2002.

The authors are with the Department of Electrical Power and Machines, Cairo University, Giza 12613, Egypt (e-mail: a.zobaa@eng.cu.edu.eg).

Digital Object Identifier 10.1109/TPWRD.2003.820194 injected by nonlinear loads. Based on some simplifying assumptions, compensator selection and system modeling at both fundamental and harmonic frequencies are derived.

On the other hand, if a nonlinear load generates significant harmonic currents locally, tuned filters may be installed to prevent the currents from being injected into the system. However, such filters are resorted only for heavily nonlinear loads because of high cost. One important side effect of adding a filter is that it creates a sharp parallel resonance point at a frequency below the notch frequency [12]. This resonant frequency must be safely away from any significant harmonic. Filters are commonly tuned slightly lower than the harmonic to be filtered to provide a margin of safety in case there is some change in system parameters. If they were tuned exactly to the harmonic, changes in either capacitance or inductance with temperature or failure might shift the parallel resonance into the harmonic. This could present a situation worse than without a filter because the resonance is generally very sharp. For this reason, filters are added to the system starting with the lowest problem harmonic. For example, installing a seventh-harmonic filter usually requires that a fifth-harmonic filter also be installed. The new parallel resonance with a seventh filter only would have been very near the fifth, which is generally disastrous.

In [13], both the equivalent source and load are considered to generate harmonics. It is assumed that the load harmonics are not sufficiently serious to suggest tuned filters, but when combined with source harmonics, the use of a pure capacitive compensator would degrade power factor and overload equipment. Consequently, an $L C$ compensator is selected. The different criteria for the design of the $L C$ compensator are discussed taking into consideration the nonlinearity of the load by using direct polytope search method.

In this paper, the manufacturer's standard values for power shunt capacitors are taken into consideration. These values are considered as constraints in the sense that the solution for the capacitor should be one of the standard values. The different criteria for the design of the $L C$ compensator are discussed by using Golden Section Search method. The reason for doing this is to compare the values obtained [13] with real practical values in the market. Reference [14] shows the voltage and reactive power ratings of shunt capacitors. The inductive reactive values are almost continuous and there is little limitation on the manufacturer's values.

\section{COMPENSATED NONLINEAR LOADS}

Consider the system shown in Fig. 1. 


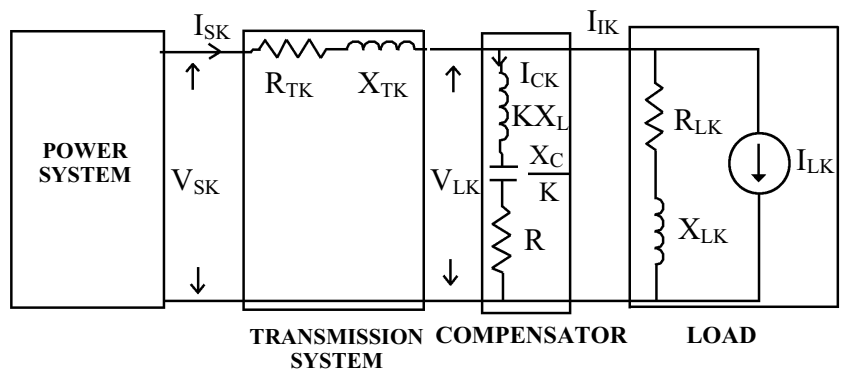

Fig. 1. Configuration of the study system.

Let $\mathrm{X}_{\mathrm{C}}$ be the capacitive reactance, $\mathrm{X}_{\mathrm{L}}$ is in inductive reactance, and $\mathrm{R}$ the compensator resistance at the fundamental frequency.

The compensating impedance $\mathrm{Z}_{\mathrm{CK}}$

$$
\mathrm{Z}_{\mathrm{CK}}=\mathrm{R}+\mathrm{j}\left(\mathrm{KX}_{\mathrm{L}}-\frac{\mathrm{X}_{\mathrm{C}}}{\mathrm{K}}\right)
$$

let $\mathrm{Z}_{\mathrm{CLK}}=\mathrm{Z}_{\mathrm{CK}}$ in parallel with $\mathrm{Z}_{\mathrm{LK}}$, let $\mathrm{Z}_{\mathrm{TLK}}=\mathrm{Z}_{\mathrm{TK}}$ in parallel $Z_{\mathrm{LK}}$, let $\mathrm{Z}=\mathrm{Z}_{\mathrm{TK}}$ in series $\mathrm{Z}_{\mathrm{CLK}}$.

After some complex algebraic manipulations, the expression for the Kth harmonic source current and load voltage are given by

$$
\begin{aligned}
I_{S K} & =\frac{V_{S K}(A R+j B R)+I_{L K}(C R)}{A_{I K}+j A_{J K}} \\
V_{L K} & =\frac{V_{S K}(C R)-I_{L K}(D R * E R)}{A_{I K}+A_{J K}}
\end{aligned}
$$

where

$$
\begin{aligned}
\mathrm{AR}= & \mathrm{R}+\mathrm{R}_{\mathrm{LK}} \\
\mathrm{BR}= & \left(\mathrm{X}_{\mathrm{LK}}+\mathrm{K} \mathrm{X}_{\mathrm{L}}-\frac{\mathrm{X}_{\mathrm{C}}}{\mathrm{K}}\right) \\
\mathrm{CR}= & \mathrm{R}_{\mathrm{CLK}}+\mathrm{j} \mathrm{X}_{\mathrm{CLK}} \\
\mathrm{DR}= & \mathrm{R}+\mathrm{j}\left(\mathrm{K} \mathrm{X}_{\mathrm{L}}-\frac{\mathrm{X}_{\mathrm{C}}}{\mathrm{K}}\right) \\
\mathrm{ER}= & \mathrm{R}_{\mathrm{TLK}}+\mathrm{j} \mathrm{X}_{\mathrm{TLK}} \\
\mathrm{A}_{\mathrm{IK}}= & \mathrm{R}_{\mathrm{TLK}}+\mathrm{R}\left(\mathrm{R}_{\mathrm{LK}}+\mathrm{R}_{\mathrm{TK}}\right) \\
& -\left(\mathrm{X}_{\mathrm{LK}}+\mathrm{X}_{\mathrm{TK}}\right)\left(\mathrm{KX} \mathrm{X}_{\mathrm{L}}-\frac{\mathrm{X}_{\mathrm{C}}}{\mathrm{K}}\right) \\
\mathrm{A}_{\mathrm{JK}}= & \mathrm{X}_{\mathrm{TLK}}+\mathrm{R}\left(\mathrm{R}_{\mathrm{LK}}+\mathrm{X}_{\mathrm{TK}}\right) \\
& +\left(\mathrm{R}_{\mathrm{LK}}+\mathrm{R}_{\mathrm{TK}}\right)\left(\mathrm{KX} \mathrm{X}_{\mathrm{L}}-\frac{\mathrm{X}_{\mathrm{C}}}{\mathrm{K}}\right) \\
\mathrm{R}_{\mathrm{TLK}}= & \mathrm{R}_{\mathrm{TK}} \mathrm{R}_{\mathrm{LK}}-\mathrm{X}_{\mathrm{TK}} \mathrm{X}_{\mathrm{LK}} \\
\mathrm{X}_{\mathrm{TLK}}= & \mathrm{R}_{\mathrm{TK}} \mathrm{X}_{\mathrm{LK}}+\mathrm{X}_{\mathrm{LK}} \mathrm{R}_{\mathrm{LK}} \\
\mathrm{R}_{\mathrm{CLK}}= & \mathrm{RR}_{\mathrm{LK}}-\mathrm{X}_{\mathrm{LK}}\left(\mathrm{KX}_{\mathrm{L}}-\frac{\mathrm{X}_{\mathrm{C}}}{\mathrm{K}}\right) \\
\mathrm{X}_{\mathrm{CLK}}= & \mathrm{RX}_{\mathrm{LK}}+\mathrm{R}_{\mathrm{LK}}\left(\mathrm{KX}_{\mathrm{L}}-\frac{\mathrm{X}_{\mathrm{C}}}{\mathrm{K}}\right) .
\end{aligned}
$$

\section{IDENTIFICATION OF SKIN EFFECT}

Reference [15] demonstrates that the representation of the power system loads and extended networks can be improved by using alternative models. The distribution system, loads, other elements, and equivalents of extended networks have been considered in detail. The models developed allow a more realistic representation of the system and, consequently, a more accurate assessment of the harmonic currents and voltages throughout the transmission network. Guidance has been provided on modeling of individual loads and on typical load composition. System tests are necessary to provide verification of the modeling methodology developed, as well as adding to the knowledge of system load characteristics. This effect will be applied in the analysis as applied in [13].

\section{HARMONIC RESONANT CONSTRAINT}

It is essential to identify the value of inductor and capacitors $\mathrm{KX}_{\mathrm{L}}$ and $\mathrm{X}_{\mathrm{C}} / \mathrm{K}$ that can cause resonance as described in [13]. A series resonance line represents all possible combinations of $X c$ and $X_{L}$ values which result in series resonance between the Thevenin impedance and compensated load at source harmonic frequency. Under these conditions, the power factor will reach a minimum. It is evident that the number of series resonance lines will depend on the number of harmonics presents in the Thevenin source. These resonance lines are obtained by setting the imaginary part of the impedance seen from the Thevenin source to zero resulting in a quadratic equation in $X_{C}$ and $X_{L}$ for any given harmonic order $K$

$$
\mathrm{A}_{1}\left(\mathrm{KX}_{\mathrm{L}}-\frac{\mathrm{X}_{\mathrm{C}}}{\mathrm{K}}\right)^{2}+\mathrm{A}_{2}\left(\mathrm{KX}_{\mathrm{L}}-\frac{\mathrm{X}_{\mathrm{C}}}{\mathrm{K}}\right)+\mathrm{A}_{3}=0
$$

where

$$
\begin{aligned}
& \mathrm{A}_{1}=\mathrm{X}_{\mathrm{TK}}+\mathrm{X}_{\mathrm{LK}} \\
& \mathrm{A}_{2}=\mathrm{R}_{\mathrm{LK}}^{2}+\mathrm{X}_{\mathrm{LK}}^{2}+2 \mathrm{X}_{\mathrm{LK}} \mathrm{X}_{\mathrm{TK}} \\
& \mathrm{A}_{3}=\mathrm{R}^{2} \mathrm{X}_{\mathrm{LK}}+\mathrm{X}_{\mathrm{TK}}\left[\left(\mathrm{R}+\mathrm{R}_{\mathrm{LK}}\right)^{2}+\mathrm{X}_{\mathrm{LK}}^{2}\right] .
\end{aligned}
$$

Solving (5) for finding $\mathrm{X}_{\mathrm{L}}$ and $\mathrm{X}_{\mathrm{C}}$

$$
\mathrm{KX}_{\mathrm{L}}-\frac{\mathrm{X}_{\mathrm{C}}}{\mathrm{K}}=\frac{-\mathrm{A}_{2} \pm \sqrt{\mathrm{A}_{2}^{2}-4 \mathrm{~A}_{1} \mathrm{~A}_{3}}}{2 \mathrm{~A}_{1}} .
$$

Hence, using only the set values for shunt capacitors, we can obtain values for the inductive reactance since (4) will then become a one variable equation in $\mathrm{X}_{\mathrm{L}}$ only.

\section{Formulation of the SEARCh Algorithm}

Each value of the reactive power ratings $\mathrm{Q}_{\mathrm{ci}}$ of the particular voltage is used to calculate the corresponding value of $\mathrm{X}_{\mathrm{ci}}$. This value is then substituted into the objective function to become one variable equation in $\mathrm{X}_{\mathrm{L}}$, which can be solved by using the golden section search method

A)

maximizing the power factor

Find $\mathrm{X}_{\mathrm{Ci}}, \mathrm{X}_{\mathrm{L}}$

$$
\text { To maximize: } \begin{aligned}
P F & =\frac{\mathrm{P}_{\mathrm{L}}}{\mathrm{V}_{\mathrm{L}} \mathrm{I}_{\mathrm{S}}} \\
& =\frac{\sum \mathrm{G}_{\mathrm{LK}} \mathrm{V}_{\mathrm{LK}}^{2}}{\sqrt{\sum \mathrm{I}_{\mathrm{SK}}^{2}+\mathrm{V}_{\mathrm{SK}}^{2}}} .
\end{aligned}
$$

Subject to $\mathrm{X}_{\mathrm{Ci}}, \mathrm{X}_{\mathrm{L}}$ is not part of solution of (4). 
B) Minimizing the transmission loss

Find $\mathrm{X}_{\mathrm{Ci}}, \mathrm{X}_{\mathrm{L}}$

$$
\text { To minimize: } \mathrm{TL}=\sum_{\mathrm{K}} \mathrm{I}_{\mathrm{SK}}^{2} \mathrm{R}_{\mathrm{TK}}
$$

Subject to $\mathrm{X}_{\mathrm{Ci}}, \mathrm{X}_{\mathrm{L}}$ is not part of solution of (4)

C) Maximizing the transmission efficiency

Find $\mathrm{X}_{\mathrm{Ci}}, \mathrm{X}_{\mathrm{L}}$

$$
\text { To maximize: } \begin{aligned}
\eta & =\frac{\mathrm{P}_{\mathrm{L}}}{\mathrm{P}_{\mathrm{S}}} \\
& =\frac{\sum \mathrm{G}_{\mathrm{LK}} \mathrm{V}_{\mathrm{LK}}^{2}}{\sum \mathrm{I}_{\mathrm{SK}}^{2} \mathrm{R}_{\mathrm{TK}}+\sum \mathrm{G}_{\mathrm{LK}} \mathrm{V}_{\mathrm{LK}}^{2}} .
\end{aligned}
$$

Subject to $\mathrm{X}_{\mathrm{Ci}}, \mathrm{X}_{\mathrm{L}}$ is not part of solution of (4).

The power factor $P F$, the transmission loss $T L$, and the transmission efficiency $\eta$ can be expressed as functions of $\mathrm{X}_{\mathrm{C}}$ and $\mathrm{X}_{\mathrm{L}}$, using the network equations. The golden section search algorithm can then be applied to find the compensator values maximizing the power factor, minimizing the transmission loss, and maximizing the transmission efficiency. The suggested algorithm [16] is discussed below.

Step 1) Choose the first value of the standard manufactured reactive power rating of capacitors in kVAR [14]

$$
\mathrm{Q}_{\mathrm{ci}}=\left\{\mathrm{Q}_{\mathrm{c} 1}, \mathrm{Q}_{\mathrm{c} 2} \ldots \mathrm{Q}_{\mathrm{cn}}\right\}
$$

where $\mathrm{n}$ is the number of discrete values available for the particular voltage rating used and $i$ has a starting value of 1.

Step 2) Using only the selected value of Qci, calculate $\mathrm{X}_{\mathrm{ci}}$ from the following equation:

$$
\mathrm{X}_{\mathrm{Ci}}=\frac{\mathrm{V}_{\mathrm{S} 1}^{2}}{\mathrm{Q}_{\mathrm{ci}}}
$$

Step 3) Substitute the value of $\mathrm{X}_{\mathrm{Ci}}$ into the objective function to become one variable problem in $\mathrm{X}_{\mathrm{L}}$.

Step 4) Using golden section search algorithm [17] to solve (5), (6), and (7) for optimal $\mathrm{X}_{\mathrm{L}}$.

Step 5) If $i=n$ stop; otherwise, replace $i$ by $(i+1)$ and go to step 1.

Step 6) After stopping, scan through to get the global minimum or maximum.

The golden section search algorithm was chosen due to that it requires fewer steps and function evaluations. The algorithm is discussed below. The following notations are used in the algorithm:

$\mathrm{L}_{\mathrm{u}}$

$\mathrm{L}_{\mathrm{L}}$

$\Delta$

$\mathrm{L}_{1}, \mathrm{~L}_{2}$

$\mathrm{f}(\mathrm{L})$

$\in \quad$ convergence criterion for the algorithm.

Given the value of $\mathrm{L}_{\mathrm{u}}, \mathrm{L}_{\mathrm{L}}$, and $\lambda=(3-\sqrt{5}) / 2$, the following steps illustrates the algorithm:
Step 1) calculate

$$
\begin{aligned}
\Delta & =\mathrm{L}_{\mathrm{u}}-\mathrm{L}_{\mathrm{L}} \\
\mathrm{L}_{1} & =\mathrm{L}_{\mathrm{L}}+\lambda \Delta
\end{aligned}
$$

and

$$
\mathrm{L}_{2}=\mathrm{L}_{\mathrm{u}}-\lambda \Delta .
$$

Evaluate $\mathrm{f}\left(\mathrm{L}_{1}\right)$ and $\mathrm{f}\left(\mathrm{L}_{2}\right)$;

Step 2) if $f\left(L_{1}\right) \leq f\left(L_{2}\right)$, go to step 7;

Step 3) set $\mathrm{L}_{\mathrm{L}}=\mathrm{L}_{1}$ and $\mathrm{f}\left(\mathrm{L}_{\mathrm{L}}\right)=\mathrm{f}\left(\mathrm{L}_{1}\right)$;

Step 4) set $\mathrm{L}_{1}=\mathrm{L}_{2}$ and $\mathrm{f}\left(\mathrm{L}_{1}\right)=\mathrm{f}\left(\mathrm{L}_{2}\right)$;

Step 5) set $\mathrm{L}_{2}=\mathrm{L}_{\mathrm{u}}-\lambda\left(\mathrm{L}_{\mathrm{u}}-\mathrm{L}_{\mathrm{L}}\right)$ and evaluate $\mathrm{f}\left(\mathrm{L}_{2}\right)$;

Step 6) go to step 10;

Step 7) set $\mathrm{L}_{\mathrm{u}}=\mathrm{L}_{2}$ and $\mathrm{f}\left(\mathrm{L}_{\mathrm{u}}\right)=\mathrm{f}\left(\mathrm{L}_{2}\right)$;

Step 8) set $\mathrm{L}_{2}=\mathrm{L}_{1}$ and $\mathrm{f}\left(\mathrm{L}_{2}\right)=\mathrm{f}\left(\mathrm{L}_{1}\right)$;

Step 9) set $\mathrm{L}_{1}=\mathrm{L}_{\mathrm{L}}+\lambda\left(\mathrm{L}_{\mathrm{u}}-\mathrm{L}_{\mathrm{L}}\right)$ and evaluate $\mathrm{f}\left(\mathrm{L}_{1}\right)$;

Step 10) if $\left(\mathrm{L}_{\mathrm{u}}-\mathrm{L}_{\mathrm{L}}\right) \geq \epsilon$, go to step 2; otherwise, stop.

Note that in order to have the algorithm to guarantee convergence, the objective functions have to be unimodal functions [18].

Due to the resonant conditions, there might be local minimums (or maximums) to which the solution will converge. To avoid this problem, the precalculated compensator values for series resonance will be used to subdivide the entire search region into numeral small regions. Within these regions, the local minimums (or maximums) are identified and, hence, the global minimum (or maximum).

In the optimization process, the resistance of the compensator reactor has been neglected due to its small value with respect to its fundamental reactance (less than 5\%) [19].

\section{EXAMPLES AND Simulated RESUlts}

Four cases of an industrial plant were simulated using the optimization method. The numerical data were primarily taken from an example in [20] where the inductive three-phase load is $5100 \mathrm{~kW}$ with a displacement factor of 0.717 . The 60 -cycle supply bus voltage is $4.16 \mathrm{kV}$ (line-to-line). Reactive power ratings for voltage of $4.16 \mathrm{kV}$ are 50,100, 150, and $200 \mathrm{kVAR}$. The data values are given in Table I.

Table II shows that when the $L C$ solution producing the optimal capacitor value does not lie within the manufacturing standards, then it is preferable to use these standard values to solve for the optimal conditions. In such a situation, there is bound to be a difference in the optimal solution from that obtained.

Table III shows a summary of the results for nonlinear load. The optimum compensation can be achieved with substantial improvement in power factor, reduction in transmission losses, and an increase in transmission efficiency. This is especially true if no manufacture constraints are imposed [13]. Results from this study indicate that having large capacitors does not mean higher power factor when nonlinear loads are fed from nonsinusoidal sources.

Comparison of the results shows that a lower short-circuit capacity corresponds to a higher power factor at the same conditions. This to be expected since with higher transmission impedance, less harmonic current will flow into the compensated load. Also it is shown that additional harmonic contents result in lower power factor. This is caused by the increase 
TABLE I

SYSTEM PARAMETERS AND SOURCE HARMONICS

\begin{tabular}{c|c|c|c|c}
\hline Parameters \& Harmonics & Case 1 & Case 2 & Case 3 & Case 4 \\
\hline Short CircuitMV A & 150 & 150 & 80 & 80 \\
\hline $\mathrm{R}_{\mathrm{T1}}(\Omega)$ & 0.01154 & 0.01154 & 0.02163 & 0.02163 \\
\hline $\mathrm{X}_{\mathrm{T1}}(\Omega)$ & 0.1154 & 0.1154 & 0.2163 & 0.2163 \\
\hline $\mathrm{R}_{\mathrm{L1}}(\Omega)$ & 1.742 & 1.742 & 1.742 & 1.742 \\
\hline $\mathrm{X}_{\mathrm{L1}}(\Omega)$ & 1.696 & 1.696 & 1.696 & 1.696 \\
\hline $\mathrm{V}_{\mathrm{SI}}(\mathrm{kV})$ & 2.4 & 2.4 & 2.4 & 2.4 \\
\hline $\mathrm{V}_{\mathrm{S} 3}\left(\% \mathrm{~V}_{\mathrm{S1}}\right)$ & 0 & 0 & 0 & 3 \\
\hline $\mathrm{V}_{\mathrm{S} 5}\left(\% \mathrm{~V}_{\mathrm{SI}}\right)$ & 5 & 7 & 5 & 5 \\
\hline $\mathrm{V}_{\mathrm{S} 7}\left(\% \mathrm{~V}_{\mathrm{S1}}\right)$ & 3 & 7 & 3 & 3 \\
\hline $\mathrm{V}_{\mathrm{S} 11}\left(\% \mathrm{~V}_{\mathrm{S1}}\right)$ & 2 & 2 & 2 & 2 \\
\hline $\mathrm{V}_{\mathrm{S} 13}\left(\% \mathrm{~V}_{\mathrm{S1}}\right)$ & 1 & 1 & 1 & 1 \\
\hline $\mathrm{I}_{\mathrm{L} 3}(\mathrm{~A})$ & 304 & 304 & 304 & 304 \\
\hline $\mathrm{I}_{\mathrm{L} 5}(\mathrm{~A})$ & 33 & 33 & 33 & 33 \\
\hline $\mathrm{I}_{\mathrm{L} 7}(\mathrm{~A})$ & 25 & 25 & 25 & 25 \\
\hline $\mathrm{I}_{\mathrm{L} 9}(\mathrm{~A})$ & 26 & 26 & 26 & 26 \\
\hline $\mathrm{I}_{\mathrm{L} 11}(\mathrm{~A})$ & 8 & 8 & 8 & 8 \\
\hline $\mathrm{I}_{\mathrm{L} 13}(\mathrm{~A})$ & 9 & 9 & 9 & 9 \\
\hline & & & &
\end{tabular}

TABLE II

SimUlated Results FOR THE OPTIMIZATION METHOD IN [13]

\begin{tabular}{l|c|c|c|c|c|c|c}
\hline Criteria & $\mathrm{X}_{\mathrm{C}}(\Omega)$ & $\mathrm{X}_{\mathrm{L}}(\Omega)$ & $\mathrm{PF}(\%)$ & $\mathrm{I}_{\mathrm{S}}(\mathrm{A})$ & $\eta(\%)$ & $\mathrm{TL}(\mathrm{kW})$ \\
\hline \multicolumn{7}{c}{ Case 1} \\
\hline Min. $T L$ & 4.06 & 0.45 & 98.85 & 705.12 & 99.66 & 5.74 \\
\hline Max. $P F$ & 3.84 & 0.40 & 99.01 & 705.34 & 99.66 & 5.74 \\
\hline Max. $\eta$ & 3.91 & 0.43 & 98.98 & 705.13 & 99.66 & 5.74 \\
\hline \multicolumn{7}{|c}{ Case 2} \\
\hline Min. $T L$ & 4.06 & 0.45 & 98.74 & 706.12 & 99.66 & 5.75 \\
\hline Max. $P F$ & 3.85 & 0.41 & 98.89 & 706.39 & 99.66 & 5.76 \\
\hline Max. $\eta$ & 3.91 & 0.43 & 98.87 & 706.13 & 99.66 & 5.75 \\
\hline \multicolumn{7}{|c}{ Case 3 } \\
\hline Min. $T L$ & 4.19 & 0.46 & 95.17 & 700.46 & 99.36 & 10.61 \\
\hline Max. $P F$ & 3.59 & 0.28 & 97.26 & 706.75 & 99.36 & 10.80 \\
\hline Max. $\eta$ & 3.95 & 0.47 & 95.19 & 701.55 & 99.37 & 10.65 \\
\hline \multicolumn{7}{|c|}{ Case 4 } \\
\hline Min. $T L$ & 4.19 & 0.47 & 95.01 & 701.24 & 99.36 & 10.64 \\
\hline Max. $P F$ & 3.60 & 0.30 & 96.75 & 709.39 & 99.36 & 10.89 \\
\hline Max. $\eta$ & 3.97 & 0.45 & 95.50 & 702.31 & 99.37 & 10.67 \\
\hline
\end{tabular}

in compensated line current due to the additional harmonics, cases 2,4 .

Based on the results and experience gained from this study, additional observations are made on the concept of power factor correction in nonsinusoidal systems.

1) The three criteria-minimization of the transmission loss, maximization of the power factor, and maximization of the transmission efficiency, lead to different optimal solutions, although the corresponding performance may be not very different.

2) Passive compensator value that would produce a unity power factor is not physically realizable.

3) Neglecting the resonant phenomena in the analysis would lead to erroneous results.

4) Due to resonant conditions, an increase of shunt compensator does not necessarily produce an improved power
TABLE III

Simulated Results For the PRESENTEd OPtimizATION Method

\begin{tabular}{l|c|c|c|c|c|c}
\hline Criteria & $\mathrm{X}_{\mathrm{C}}(\Omega)$ & $\mathrm{X}_{\mathrm{L}}(\Omega)$ & $\mathrm{PF}(\%)$ & $\mathrm{I}_{\mathrm{S}}(\mathrm{A})$ & $\eta(\%)$ & $\mathrm{TL}(\mathrm{kW})$ \\
\hline \multicolumn{7}{|c}{ Case 1} \\
\hline Min. $T L$ & 4.61 & 0.79 & 96.31 & 713.22 & 99.65 & 5.87 \\
\hline Max. $P F$ & 3.39 & 0.34 & 98.19 & 715.79 & 99.65 & 5.91 \\
\hline Max. $\eta$ & 4.27 & 0.79 & 96.55 & 714.14 & 99.65 & 5.89 \\
\hline \multicolumn{7}{|c}{ Case 2} \\
\hline Min. $T L$ & 4.61 & 0.79 & 96.28 & 714.02 & 99.65 & 5.88 \\
\hline Max. $P F$ & 3.39 & 0.34 & 98.07 & 716.87 & 99.65 & 5.93 \\
\hline Max. $\eta$ & 4.27 & 0.79 & 96.51 & 714.95 & 99.65 & 5.90 \\
\hline \multicolumn{7}{|c}{ Case 3 } \\
\hline Min. $T L$ & 4.61 & 0.75 & 89.47 & 703.57 & 99.36 & 10.71 \\
\hline Max. $P F$ & 3.72 & 0.33 & 97.04 & 704.33 & 99.37 & 10.73 \\
\hline Max. $\eta$ & 4.27 & 0.74 & 89.77 & 704.25 & 99.36 & 10.72 \\
\hline \multicolumn{7}{|c|}{ Case 4 } \\
\hline Min. $T L$ & 4.61 & 0.75 & 89.13 & 706.58 & 99.35 & 10.80 \\
\hline Max. $P F$ & 3.72 & 0.33 & 96.66 & 707.08 & 99.36 & 10.81 \\
\hline Max. $\eta$ & 4.27 & 0.74 & 89.42 & 707.38 & 99.36 & 10.82 \\
\hline
\end{tabular}

factor operation as predicted by fundamental frequency analysis.

5) Due to the uncertainties in system parameter data, one might consider a suboptimal compensation if resonant conditions occur at various compensator values very close to the optimal values.

6) The harmonic voltage distortion generated by a nearby customer could produce, to another customer, a low power factor-operating problem of which a simple and economic solution may not be feasible.

7) The analysis is also applicable for more general loads, even if the structure is more complex than in Fig. 1. It suffices to use suitable $G_{L K}$ and $B_{L K}$ characteristics.

8) It can be concluded that erroneous results are obtained if the source is assumed to be devoid of harmonics or that the source impedance is neglected as in the conventional methods [3], [16], [17].

\section{CONCLUSION}

For nonlinear loads, it is necessary to use $L C$ compensators. Such compensators have dual purposes. The first is that it acts as a compensator to improve the power factor of the nonlinear loads. Second, it acts as a filter of the harmonic load currents, thus preventing the proliferation of the network with these currents. One problem that is addressed is whether the values obtained from theoretical optimization solution can be obtained from standard manufactured values. Depending on the voltage, manufacturers have discrete capacitors values. For this reason, a new solution algorithm has to be developed taking into consideration the discrete nature of standard values. Finally, the presented method is only attractive if the number of capacitors to choose from is limited. However, the problem may become complicated and lengthy if the number of capacitors is very high and if the inductor values have to be discrete as well. Under such conditions, an intelligent way of searching has to be found. 
Ongoing research effort consists of the modification of this method to determine the effect of time variation of system impedance and voltage harmonics. Note that this effort is in conjunction with the concern and activities in the IEEE Power Engineering Society on harmonics and their effects on the power system operation.

\section{REFERENCES}

[1] N. L. Kusters and W. J. M. Moore, "On the definition of reactive power under nonsiusoidal conditions," IEEE Trans. Power App. Syst., vol PAS-79, pp. 1845-1854, Sept./Oct. 1980.

[2] J. J. Grainger and S. H. Lee, "Optimum size and location of shunt capacitor for reduction of losses on distribution feeders," IEEE Trans. Power App. Syst., vol. PAS-100, pp. 1105-11 118, Mar. 1981.

[3] J. L. Willems, "Power factor correction for distorted bus voltages," Elect. Mach. Power Syst., vol. 13, pp. 207-218, 1987.

[4] R. T. Saleh and A. E. Emanuel, "Optimum shunt capacitor for power factor correction at busses with lightly distorted voltage," IEEE Trans. Power Delivery, vol. PWRD-2, pp. 165-173, Jan. 1987.

[5] B. Duro, V. S. Ramsden, and P. Muttik, "Minimization of active filter rating in high power hybrid filter systems," in Proc. IEEE Int. Conf. Power Electron., vol. 2, 1999, pp. 1043-1048.

[6] D. Zaninelli, "Nonlinear passive filters in power systems," in Proc. IEEE Power Eng. Soc. Summer Meeting, vol. 2, 2000, pp. 773-777.

[7] W. Jewell, W. L. Miller, and T. Casey, "Filtering dispersed harmonic sources on distribution," IEEE Trans. Power Delivery, vol. 15, pp. 1045-1051, July 2000.

[8] I. Kasikci, "A new method for power factor correction and harmonic elimination," in Proc. Harmon. Power Quality 9th Int. Conf., vol. 3, 2000 , pp. 810-815.

[9] O. Garcia, J. A. Cobos, R. Prieto, P. Alou, and J. Uceda, "Power factor correction: a survey," in Proc. IEEE Power Electron. Specialists Conf., vol. 1, 2001, pp. 8-13.

[10] J. Phinney and D. J. Perreault, "Filters with active tuning for power applications," in Proc. IEEE Power Electron. Specialists Conf., vol. 1, 2001, pp. 363-370.

[11] S.Sangsun Kim and P. N. Enjeti, "Anew hybrid active power filter (APF) topology," in Proc. 16th Annu. IEEE Appl. Power Electron, vol. 2, 2001, pp. 835-841.

[12] R. C. Dugan, M. F. McGranaghan, and H. W. Beaty, Electrical Power Systems Quality. New York: McGraw-Hill, 1996.

[13] M. M. Abdel-Aziz, E. E. Abou El-Zahab, A. M. Ibrahim, and A. F. Zobaa, "LC compensators for power factor correction of nonlinear loads," in Proc. Int. Conf. Harmon. Quality Power. Rio de Janeiro, Brazil, Oct. 6-9, 2002, ICHQP02.

[14] IFEEE Standards for Shunt Power Capacitors, IEEE Std.-18-1992, 1992.

[15] P. F. Ribeiro, "Tutorial on harmonics modeling and simulation," in Proc. IEEE Power Eng. Soc. Winter Meeting, 1998.

[16] I. M. El-Amin, S. O. Duffuaa, and A. U. Bawah, "Optimal shunt compensators at nonsinusoidal bus bars," IEEE Trans. Power Syst., vol. 10 , pp. 716-723, May 1995.

[17] R. F. Chu and R. H. Avandano, "A direct method for identifying the optimal power factor correction in nonsinusoidal systems," IEEE Trans. Power Apparat. Syst., vol. PAS-104, pp. 959-964, Apr. 1985.

[18] D. A. Pierre, Optimization Theory With Applications. New York: Wiley, 1969

[19] G. G. Richards, O. T. Tan, P. Klinkhachorn, and N. I. Santoso, "Costconstrained power factor optimization with source harmonics using LC compensators," IEEE Trans. Ind. Electron., vol. IE-34, pp. 266-270, May 1987.
[20] IEEE Guide for Harmonic Control and Reactive Compensation of Static Power Converters, IEEE Std.-519-1992, 1992.

Mohamed Mamdouh Abdel Aziz (M'80) received the B.Sc., M.Sc., and Ph.D degrees in electrical power and machines from Cairo University, Giza, Egypt, in 1970, 1972, and 1975, respectively.

Currently, he is a Professor of electrical power and machines at Cairo University. He was an Instructor in the Department of Electrical Power and Machines at Cairo University from 1970 to 1972 . Following graduation, he was a Teaching Assistant in the Department of Electrical Power and Machines at Cairo University from 1972 to 1975 . On the technical side, he is author or co-author of many refereed journal and conference papers. His areas of research include cables, contact resistance, harmonics, power quality, photovoltaic systems, and wind energy systems.

Essam El-Din Abou El-Zahab received the B.Sc. and M.Sc. degrees in electrical power and machines from Cairo University, Giza, Egypt, in 1970 and 1974, respectively. He received the Ph.D. degree in electrical power from Paul Sabatier University, Toulouge, France, in 1979.

Currently, he is a Professor in the Department of Electrical Power and Machines at Cairo University. He was an Instructor in the Department of Electrical Power and Machines at Cairo University from 1970 to 1974. On the technical side, he is author or co-author of many refereed journal and conference papers His areas of research include protection systems, renewable energy, and power distribution.

Ahmed Mohamed Ibrahim received the Ph.D. degree in electrical power engineering from Cairo University, Giza, Egypt.

His research interests include generation and utilization of electric energy.

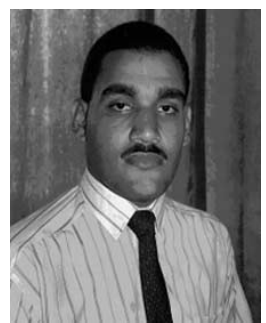

Ahmed Faheem Zobaa (M'01) received the B.Sc. (hons.), M.Sc., and Ph.D. degrees in electrical power and machines from the Faculty of Engineering at Cairo University, Giza, Egypt, in 1992, 1997 and 2002

Currently, he is an Assistant Professor in the Department of Electrical Power and Machines at Cairo University. He was an Instructor in the Department of Electrical Power and Machines with the Faculty of Engineering at Cairo University from 1992 to 1997 and a Teaching Assistant from 1997 to 2002 . He is author or co-author of many refereed journal and conference papers. His areas of research include harmonics, compensation of reactive power, power quality, photovoltaics, wind energy, education, and distance learning. He is an Editorial Board member for International Journal of Power and Energy Systems and Electric Power Components \& Systems Journal.

Dr. Zobaa is a member of the IEEE Power Engineering/Industry Applications/Industrial Electronics/Power Electronics Societies and the International Solar Energy Society. He regularly reviews papers for eight IEEE TRANSACTIONS, especially all IEEE/Power Engineering Society transactions and five journals in his areas of interest. 